\title{
Extensive Evolutionary Game Analysis for Taxi Strike Based on Wright Manifold and Mental Model
}

\author{
Ruirui Chai ${ }^{1}$, Jingfeng Chen ${ }^{2, *}$ \\ ${ }^{1}$ School of Management Science and Engineering, Dongbei University of Finance and Economics, 116025, Dalian, China \\ ${ }^{2}$ Health Management Centre, the First Affiliated Hospital of Zhengzhou University, 450052, Zhengzhou, China \\ * Corresponding author. Email: chairuirui2013@126.com
}

\begin{abstract}
To balance the irresistible new trend of the chauffeur-driven car and the uninterruptible protests of the traditional taxi industry, we initially construct extensive form game model of both players, and then respectively apply Wright manifold and mental model to analyze the dynamic evolution equilibrium. Finally, we take the Shenyang taxi strike event as example, to analyze evolutionary dynamic equilibrium. Among them, the Wright manifold is an ideal equilibrium solution. Furthermore, mental model can reveal the evolutionary equilibrium process and influence factors. More importantly, the government can promote the efficiency and sustainability in the taxi industry by strengthening the chauffeur-driven car's supervision.

Keywords: Extensive evolutionary game, wright manifold, mental model, extensive form game, taxi strike event

\section{INTRODUCTION}

Since 2010 USA uber came out, and 2014 China's "didi", "kuaidi", "shenzhou" and other chauffeur-driven cars sprung up with high quality service, ultra-low price, fast and convenient taxi way, these chauffeur-driven cars rapidly grabbed travel market share. Moreover, that caused incalculable impact on the traditional taxi monopoly industry. Consequently, behind the explosive growth of the chauffeur-driven car, there occurred a series of violent protests in taxi industry. Since 2014, Uber in New York,

researches the bounded rational behavior in groups and corresponding adaptive learning course (Weibull, 1995). However, it still faces some challenges when evolutionary game is applied to taxi protesters of potential entrants. Therefore, to solve these challenges, we study taxi protesters of potential entrants through two different ways, subgame monotonicity model and mental model. In Section 2 analyzes the extensive form game model of the chauffeur-driven car and taxi. In Section 3 and Section 4, by two different models, researches extensive form evolutionary game. Section 5 presents a case analysis base on the Shenyang taxi strike event. Finally, conclusions are given in Section 6.
\end{abstract} Boston, England, France, India, Brazil and many other countries have suffered the most massive demonstrations continuously (Chen, 2015). And in China, since 2015, in Shenyang, Chongqing, Beijing, Zhengzhou and other cities "didi", "kuaidi" also suffered serious protests (Liu, 2015). Therefore, how to balance the irresistible new trend of the chauffeur-driven car as the representative of the "Internet plus traffic" and the uninterruptible protests of the traditional taxi industry with its monopoly interests damaged, which challenges the government's policy formulation, but also draws the high attention of scholars in different fields.

In taxi strike event involving the game of the benefits of the chauffeur-driven car and taxi groups, therefore the study of the interest's equilibrium problem between different groups can provide theoretical guidance to solve the conflict of the chauffeur-driven car and taxi group. However, as a game theory problem between the chauffeur-driven car and taxi group, traditional game theory is limited to the "super-rational" assumption in a fixed environment, which is difficult to be applied to the potential entrants with bounded rationality, even irrational behavior of protesters. With rapid growth in the 1990's, evolutionary game theory

\section{EXTENSIVE FORM GAME MODEL OF CHAUFFEUR-DRIVEN CAR AND TAXI}

For two-player extensive form game in Figure 1, if in a new travel market, the chauffeur-driven car $I$ has two strategies \{Enter, Not enter\}. When the chauffeur-driven car $I$ does not enter a travel market, the taxi $J$ alone obtains the value $b_{1}$, where $b_{1}$ is defined that the taxi driver income minus high "hand-in money", fuel surcharge, management fees. If the chauffeur-driven car $I$ enters the new market, the taxi $J$ has two strategies \{Cooperation, Protest\}, when the taxi $J$ takes cooperation strategy, the taxi group $I$ obtains the value $b_{2}$, the chauffeur-driven car $I$ earns the value $a_{1}$. And when the taxi $J$ takes protest strategy, in order to maintain social stability, the government will aggravate the punishment for the chauffeur-driven car, the special car I's income is $a_{2}-f$, while the taxi $J$ 's outcome is $b_{3}-c_{1}$, where $c_{1}$ is the taxi's protest costs. Suppose when the taxi $J$ takes cooperation strategy, the earning from the convenient taxi software outweighs the benefits of protest strategy. Thus, the 
subgame perfect Nash equilibrium path in Figure 1 is

(Enter, Cooperate) with the outcome of $\left(a_{1}, b_{2}\right)$.

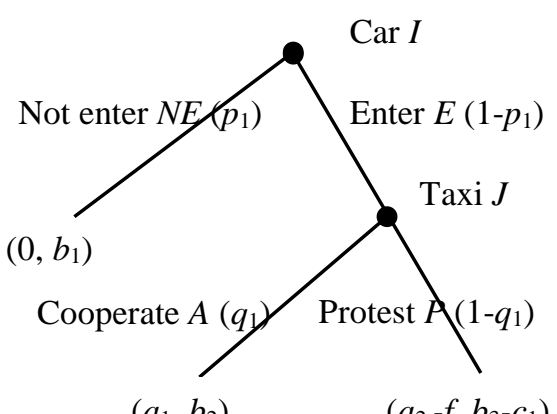

Figure 1 Extensive stage game of taxi strike

Table 1 Strategic stage game of taxi strike

\begin{tabular}{|l|l|c|c|}
\hline \multicolumn{2}{|c|}{} & \multicolumn{2}{|c|}{ Taxi $J$} \\
\cline { 3 - 4 } \multicolumn{2}{|c|}{} & Cooperate $A$ & Protest $B$ \\
\hline \multirow{3}{*}{$\begin{array}{l}\text { Chauffeur- } \\
\text { driven car } I\end{array}$} & Not enter $C$ & $0, \underline{b}_{1}$ & $\underline{0}, \underline{b}_{1}$ \\
\cline { 2 - 4 } & Enter $E$ & $\underline{a}_{1}, \underline{b}_{2}$ & $a_{2}-f, b_{3}-c_{1}$ \\
\hline
\end{tabular}

\section{SUBGAME MONOTONICITY IN EXTENSIVE FORM EVOLUTIONARY GAME}

Along the thought of transformation extensive form game into strategic/normal form game, Cressman (2000) developed the theory of subgame monotonicity for extensive form games to model evolutionary process. For the example of extensive form game of taxi strike in Figure 1 , it can be transformed into the strategic form game as shown in Table 1. According to the typical replicator dynamic function, from the Table 1, the replicator dynamic function of the taxi group taken the "Cooperation" strategy is

$$
d q_{1} / d t=q_{1}\left(1-p_{1}\right)\left(1-q_{1}\right)\left[b_{2}-\left(b_{3}-c_{1}\right)\right]=q_{1}\left(1-p_{1}\right)\left(1-q_{1}\right)\left(b_{2}-b_{3}+c_{1}\right)
$$

Because of $b_{2}>b_{3}-c_{1}$, the frequency $q_{1}$ is strictly increasing along interior trajectories for the replicator dynamic, as long as not all chauffeur-driven car take the "Not enter" strategy, $p_{1} \neq 1$. Similarly, for the chauffeur-driven car $I$, the replicator dynamic function taken the "Not enter" strategy is

$$
d p_{1} / d t=p_{1}\left(1-p_{1}\right)\left[q\left(a_{2}-a_{1}-f\right)-\left(a_{2}-f\right)\right]
$$

Now we discuss the Evolutionary Equilibrium, according to the two-player replicator dynamic functions (1) and (2). If $q\left(a_{2}-a_{1}-f\right)<\left(a_{2}-f\right) \quad, \quad a_{2}-f<0 \quad$.that is $\frac{f-a_{2}}{f+a_{1}-a_{2}}<q_{1}<1$, the frequency $p_{1}$ is strictly decreasing. Combined the increasing frequency $\mathrm{d} q_{1} / \mathrm{d} t>0$ with the decreasing frequency $\mathrm{d} p_{1} / \mathrm{d} t<0$, the only Evolutionary Equilibrium (EE) is the strategies profile (Enter, Cooperation), which is also subgame perfect Nash equilibrium.

If $0<q_{1}<\frac{f-a_{2}}{f+a_{1}-a_{2}}$, the frequency $p_{1}$ is strictly increasing until reached at $p_{1}=1$. In this case, the frequency $q_{1}$ is changeless according to the equation (3). Thus, the 
Evolutionary Equilibrium is located in an interval of boundary line, which is $p_{1}=1$ and $0<q_{1}<\frac{f-a_{2}}{f+a_{1}-a_{2}}$.

Cressman (2000) defined the special invariant surface in equation (2). Then, we obtain the Wright manifold as presented in equation (3), which can keep the monotonicity of the overall dynamic and of the subgame dynamic.

$W=\left\{(p, q) \in \Delta^{2} \times \Delta^{2} \mid q^{*}=\frac{f-a_{2}}{f+a_{1}-a_{2}}\right\}$

\section{MENTAL MODELS OF PLAYERS IN EXTENSIVE FORM EVOLUTIONARY GAME}

The concept of "mental model" is originated in the field of cognitive psychology, which is a mental mechanism for the purpose of describing the cognitive system objectives and format, explaining the system function, and observing the system current state, and predicting the system future state (Rouse and Morris, 1986; Bernergård and Mohlin, 2019).

Given the mental model and relevant feasible strategies of enter in Figure 1, the replicator dynamic function of taxi group taking the "Cooperation" strategy is

$d q_{1} / d t=q_{1}\left(1-q_{1}\right)\left[b_{2}-b_{1}\right]$

According to equation (4), the action of taxi group $J$ relies on the value $b_{1}$ and $b_{2}$. When the value $b_{1}$ is larger than the value $b_{2}$, the action of taxi group $J$ should converge to the "Protest", otherwise the action of taxi group $J$ should converge to the "Cooperation"

Similarly, for chauffeur-driven car I, the replicator dynamic function taking the "Not enter" strategy is

$d p_{1} / d t=-p_{1}\left(1-p_{1}\right) a_{1}<0$

According to equation (5), the action of chauffeur-driven car I should converge to the "Enter". Thus, the equilibrium outcome of chauffeur-driven car and taxi also relies on the value $b_{1}$ and $b_{2}$

\section{CASE ANALYSIS BASED ON THE SHENYANG TAXI STRIKE EVENT}

According to some professional online medias, such as people.com.cn (Wang, 2015), caixin.com etc., on January 4, 2015, Shenyang city, Liaoning province in China, thousands of taxi struck collectively, one of the main reasons is that the taxi drivers expressed their dissatisfaction on the rise of "didi" taxi and "kuaidi" taxi, just like Uber in other countries. After this incident, the chauffeur-driven car is identified as "illegal vehicles", and will be cracked down severely by the Shenyang government.

Analyzing the game benefits of participants in Shenyang taxi strike event: when chauffeur-driven car does not enter the travel market, the average monthly income of the taxi driver is $b_{1}=¥ 5000$. When chauffeur-driven car enters the travel market, meanwhile, the taxi driver take cooperation strategy, the average monthly income of the taxi driver is $b_{2}=¥ 3000$, the income of the chauffeur-driven car is equivalent to three times of the taxi driver's income, namely $a_{1}=¥ 9000$. While the taxi driver take protest strategy, because of the less cost of telephone fee and WeChat fee, assumes $c_{1}$ is $¥ 100$, and the strike only occur one day, the income of the taxi driver is $b_{3}=¥ 2900$. However, if the chauffeur-driven car continue to operate, it will earn $a_{2}=Y$ 9000 , and may suffer from fines of $¥ 30000$ to $¥ 100000$, assumes $f=$ - $¥ 49000$.

Combining with the evolutionary game analysis of Subgame monotonicity and mental model, in Subgame monotonicity model, (Enter, Cooperate)* and (Not enter, Protest) are both pure strategy Nash equilibrium, the former being subgame perfect and distinguished by an asterisk. The latter is contained in the connected NE component $W=\left\{(p, q) \in \Delta^{2} \times \Delta^{2} \mid p=1,0 \leq q^{*} \leq 0.8\right\}$, as shown in Figure 2(a).While in mental model, the evolutionary equilibrium outcome of chauffeur-driven car and taxi is (Enter, Protest), which is consistent with the emergency disposal scheme in the Shenyang taxi strike event, as shown in Figure 2(b).

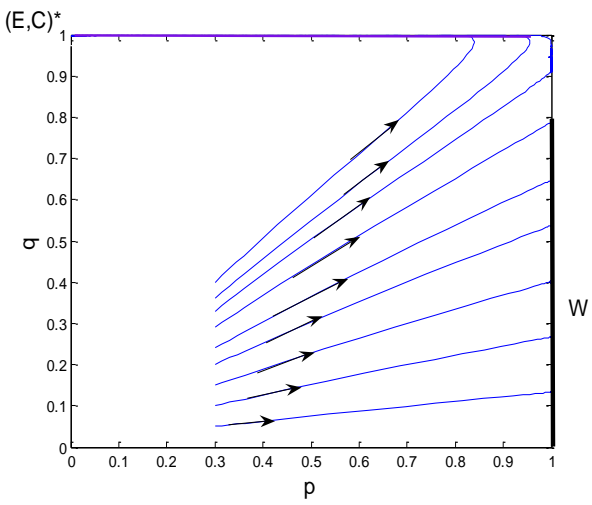

(a)

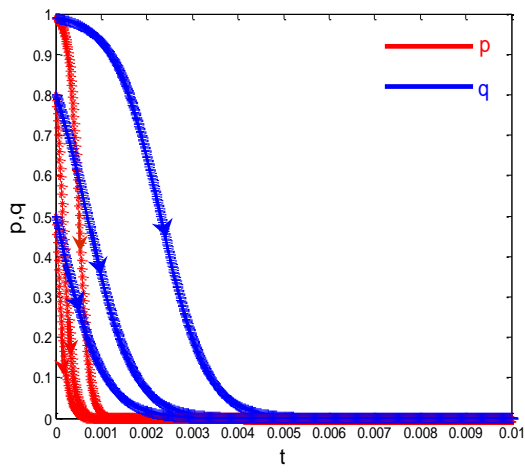

(b) 


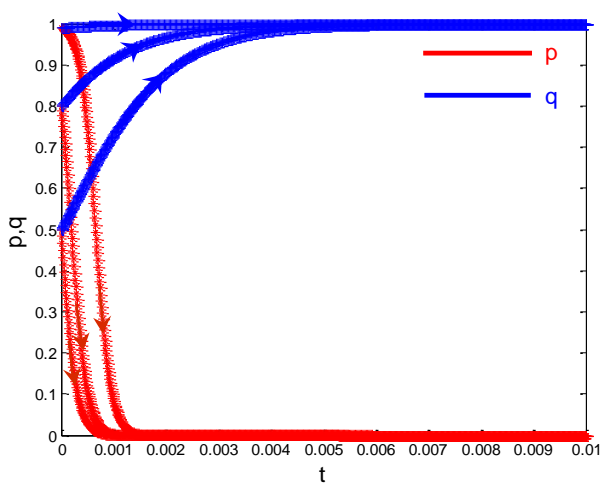

(c)

Figure 2 Strategy selection's dynamic evolution trajectories of Chauffeur-driven car and taxi group

When the chauffeur-driven car enters the travel market, it will cause a great impact on the tradition taxi industry. If the government responds to the market and makes relevant policies timely, such as strengthens the "illegal vehicle" regulation, increases the chauffeur-driven car's management fee, reduces the taxi's "hand-in money" and increases fuel subsidies etc.. Suppose in the Shenyang taxi strike, the value of the chauffeur-driven car $I$ reduces to $a_{1}=$ $¥ 7000$, while the taxi $J$ increases to $b_{2}=¥ 6000$, now the evolutionary equilibrium outcome of chauffeur-driven car and taxi is (Enter, Cooperation), which may be a better equilibrium outcome in the real society, as shown in Figure 2(c).

\section{CONCLUSION}

From the above analysis, the government plays a vital role in the taxi strike event. In order to effectively solve interest conflict between the chauffeur-driven car and taxi, we respectively apply the Wright Manifold and mental model to analyze the evolutionary dynamic equilibrium. Among them, the outcome of Wright manifold is an ideal equilibrium solution, while mental model can analyze the evolution process of equilibrium, identify the influence factors of the evolutionary equilibrium and draw some important conclusions. Only when the government strengthens the chauffeur-driven car's supervision, hits "illegal vehicles" operation, reduces the taxi "hand-in money" to enhance competitiveness, can ensure residents travel market healthy and sustainable development.

\section{REFERENCES}

[1] X. Chen. Uber: have a hit again in Europe, from a golden bowl to illegal operation. World Vision, 2015,4:56-57.

[2] Liu Lulu. The monopoly behavior analysis and countermeasures of the taxi strike $[\mathrm{J}]$. Legality Vision, 2015, 14: 223-224.
[3] J. W. Weibull, Evolutionary game theory, MIT Press, Boston, MA, 1995.

[4] R. Cressman, Subgame monotonicity in extensive form evolutionary games, Games and Economic Behavior, 2000, 32(2), 183-205.

[5] W. B. Rouse and N. M. Morris, On looking into the black box: Prospects and limits in the search for mental models, Psychological Bulletin, 1986.100(3), 349-363.

[6] Bernergård and E. Mohlin, (2019). Evolutionary selection against iteratively weakly dominated strategies, Games and Economic Behavior, forthcoming.

[7] L. Wang, Shenyang taxi strike for "car software: not for "One Yuan" [EB/OL]. people.com.cn, 2015-01-09. http://leaders.people.com.cn/n/2015/0109/c217816-263 56475.html. 